\title{
Fomsumerism: A Theoretical Framework
}

\author{
Metin $\operatorname{Argan}^{1} \&$ Mehpare Tokay-Argan ${ }^{2}$ \\ ${ }^{1}$ Faculty of Sport Sciences, Anadolu University, Eskisehir, Turkey \\ ${ }^{2}$ Department of Tourism Management and Hospitality, School of Applied Sciences, Bilecik Seyh Edebali \\ University, Turkey \\ Correspondence: Metin Argan, Department of Sport Management, Sport Science Faculty, Anadolu University, \\ Eskisehir, Turkey. Tel: 90-222-335-0580.
}

Received: April 12, $2018 \quad$ Accepted: April 28, $2018 \quad$ Online Published: May 14, 2018
$\begin{array}{ll}\text { doi:10.5539/ijms.v10n2p109 } & \text { URL: https://doi.org/10.5539/ijms.v10n2p109 }\end{array}$

\begin{abstract}
A new mode of social media-based phenomenon regarding relationship between fomo and consumption, namely fomsumerism, points out a new paradigm or point of view in terms of marketing. This article is a pioneering theoretical work as an approach from the perspective of combination of fomo and consumption. The aim of this article was to conceptualize the fomsumerism in terms of consumer behavior and to discuss this phenomenon, concept or theory. This study provides needed clarity for scholars approaching this topic. Consumption regarding fomo, fomsumerism, is depend on a sense of social media sharing and it is important to individual and social identity through shared product, service and experiences. In conclusion, this theoretical framework suggests it may be important to reveal the notion that fomsumerism in general represents the hidden patterns of consumption behavior of social media in today's world. This paper contributes to marketing theory by developing a conceptual approach that explains and offers implications pertaining to the relationship between fomo and consumption in the age of social media.
\end{abstract}

Keywords: fomo, fomsumer, fomsumerism, fomsumerist, fomsumer behavior, consumer behavior.

\section{Introduction}

Advances in internet and communication technology and particularly social media have enabled a change of consumer behavior. Social media use is widespread: nearly 89 percent of those 18-29 percent and 72 percent of all adults use social media (Ward et al., 2018). No doubt, the internet technologies which have taken place since the 2000s have catapulted user interactions in the center of marketing. Social media may be considered as an important marketing to reach a large target audience and to highlight product message in a reference group. Studies regarding Fomo, as an abbreviation of "fear of missing out", have grown in breadth and depth since the 2010s, encompassing specific areas of research, such as social media addiction. Social media not only shape consumption but also cause new emotional patterns to emerge such as fomo.

In recent years, however, a paradigm change has taken place in the marketing by active role of social media in people live. Hence, the rising influence of social media on marketing is arguably one of the most influential developments in consumer behavior in the last decades. Nowadays, social media plays an important role in shaping consumption, sharing experiences, creating awareness, branding self and so on. This role is associated with the emergence of relationship between feelings in platform of social media (e.g.fomo) and consumption patterns. The development of internet and social media dominates marketing field as well as many other fields. One of the repercussions of social media on marketing is fomo, which is characterized as "fear of missing out". Fomo is an individual's underlying feeling in social media. A consumer who exhibits fomo behavior can be called fomsumer.

Especially, today's many teenagers grow up using social media tools, such as Instagram and Facebook, as an integral part of their everyday life. Young generation and millennials, generally, have satisfied with social media to decide, in their preferences, what, why, where, and how to participate to an event, such as party, movie, social meeting, sport game etc. Teens use social media channels, such as Facebook and Instagram, as hangouts and spend hours on these social media channels because of fomo (Coons and Chen, 2014). In this sense, fomo is currently characterized as a widely-accepted phenomenon. For example, according to the results of research conducted by JWT Intelligence (2012), although only $8 \%$ of the participants indicated that they heard of this 
concept, $70 \%$ of the adult millennials (18-34 year olds) indicated that they were completely or somewhat associated with this concept (Abel et al., 2016). According to Hayran et al. (2017, 2016), 81\% of 936 participants stated that they experienced fomo at least occasionally or more frequently; this result and similar results support that fomo is a common phenomenon. Consumption from social network sites (SNS) among teens has exploded in recent years (Doster, 2013).

Feeling related issues, such as fomo is assumes as a part of positively impact of consumption patterns in increasing levels in participation. Traditionally, the majority of research on fomo, while associating with the spread of internet addiction, has evaluates as self. Until now, however, few studies have investigated the other side of the coin and adopted a missing out perspective when seeking to explain participation in the social media. Most studies of the fomo have adopted an internet using approach, focusing upon how to explain how individuals feel in the platform of social media and developing approach to evaluate the reaction in the social media context. Whereas, the fomsumer dimension of the phenomenon should be addressed. To do so is important. In this respect, fomsumerism may be viewed as a notion for relationship between feeling and consumption.

Research on fomo has been carried out regarding many different context, but it has rarely been considered behavior of fomsumers or indeed consumption dimension of fomo. While social media does play an important role in consumption phenomenon, the approaches regarding consumption patterns insufficient to fully explain the relationship between cause and effect. Despite the increasing tendency of fomo on consumer behavior, there have been a low number of reported researches or theoretical papers. However, it is important to note that theoretical studies that reveal the relationship between fomo and consumerism will contribute greatly to the related literature. Therefore, the aim of this article is to draw the theoretical framework about fomsumerism. In this article we theoretically explore the phenomenon or paradigm of fomo and consumption as a combination of fomsumerism. The aim in this paper, therefore, is to evaluate social media members' behavior for acquiring goods and services in the social media world. As reviewed below, discussions on fomsumerism exist in many different online platform.

\section{Fomo-Based Consumption or Vice Versa}

The association between fomo and consumption is a result of new paradigm that assumes new perspectives regarding marketing and consumer behavior. Consumption phenomenon is a critical aspect of broad debates about the fear of missing out (fomo). One thing is clear that social media will completely shape or affect lives of new consumer typology who have decided according to the influences and approaches of other consumers in the friend groups. Given the posts of social media of causing out a product or activity choice (e.g., appreciation, social support), it would be rational for the consumer to evaluate these social media messages in terms of perceived benefits of social acceptance. According to explanations gained from experience, fomo is increasingly prevalent through social media and sharing experience on products, services, events and moments by individuals is normalizing this feeling. Social media-driven consumers (especially millennials or teenagers) tend to have fewer social risks and more social acceptance than traditional consumers to pursue social media and thus they are generally more available and able to take part in platforms of the new media.

Research that looks specifically relationship between consumption and fomo has been very limited. Previous research on fomo has examined several aspects of the issue in terms of an emotional experience felt by individuals (McDermott, 2017), the relationship between fomo and personality or self and the assessment that have been indicated life satisfaction to address the phenomenon. Additionally, a considerable amount of the past research surrounding fomo has focused on multiple identities (Larkin, \& Fink, 2016), social media involvement, anxiety, and feelings of inadequacy (Abel, Buff, \& Burr, 2016). The symbiotic relationship between fomo and consumption is a fundamental part of social media marketing studies. Consumption regarding fomo-based emotion, behavior, and mood can be defined as fomsumption. Within this academic field, fomsumption in relation to social media participation and especially that of young consumers remains largely unexamined. Existing works on fomo not to address the dimension of consumer behavior, beyond certain aspects of psychological feeling and mood.

Another ongoing shortfall of fomo perspective, as devised and examined by Przybylski et al. (2013), is that it almost omits to take into account consumption engagement or behavior of participation, such as product or event involvement, participation in experience. Many of research regarding fomo do examine the phenomenon as the emotions felt by one person in the face of social media sharing. But association with consumption is largely absent from many of fomo studies. In particular, it tries to uncover whether it is possible to apply the 'fomo' devised by Przybylski et al. (2013) to consumption among social media users and to what extent the term 'mainly consumption focused fomo' might be appropriate, especially in social media marketing. This article 
firstly fill gaps in the existing literature on fomsumption, fomsumer and fomsumerism. Fomo-based consumption initiated the conceptual model by Hodkinson (2016), who examined variables regarding fomo-based consumer behavior. This model basically includes personal variables, situational variables, socio-cultural variables, cognitive and affective responses to fomsumer and cognitive and affective responses of post-decision. Overall, it is apparent that theoretical studies on fomo-directed consumption is still limited compared to other dimensions of social media (e.g. branding, satisfaction, intention) and requires further investigation, particularly within the marketing context. To understand the full scope of the past research on this issue, this conceptual framework examines both of research on social media and some other associate theories.

\section{Notion of Fomsumerism}

An issue that arises with the use of social media is that how social media-oriented changes in consumer behavior affected the new paradigm as fomsumerism. To take this conceptualization of certain social media contexts further, we suggest a new term - fomsumerism - as a form of social media within the context of consumer behavior. A new mode of social media-based phenomenon regarding relationship between fomo and consumption, namely fomsumerism, points out a new paradigm or point of view in terms of marketing. Consumption regarding fomo, fomsumerism, is depend on a sense of social media sharing and it is important to individual and social identity through shared product, service and experiences. Notably, the concept of fomsumerism acknowledges the satisfaction and pleasure of participating in social media, rather than a product. There was no dictionary definition on fomsumerism, until now. Hybridization of 'fomo-consumer' and 'fomo-consumerism' seems particularly useful to define how fomsumer or fomsumerism can be understood or defined. In the broadest sense, we can define a fomsumer as 'person who tends to the consumption tendency because of the fear of missing out'. In cases of social media sharing, the desire to be in the experience or feeling underlying jealousy can take action the consumption. Therefore, it will be meaningful to relate fomsumerism to social media behaviors. In the broad manner, fomsumerism refers to notion that consumption behaviors have been done in the social media environment. Similarly, it may be broadly defined as "the importance a consumer attaches to interactions and shares of social media". Fomsumerism refers to a "notion of consumption for individual, social needs and desires, a way of sharing by social media, opinion, or tendency based entirely upon interactions".

The most important phenomenon that triggers the emergence of the fomo-based consumption is the sharing, liking and interpretation. Pivotal in this evolution in the way individuals can share their experiences is the development of the self on social media, which has globalized selfie based application. Selfie, for instance, has increased the reaching capabilities of experience based products to spread among the great people in social media or through virtual word-of-mouth. This capability provides a means to distribute the product, which involves a brand getting an awareness with an individual who does have great opportunity to share it among potential target individuals.

Moreover, fomsumerism may be viewed as a tendency to consume for the liking of others and envy, or as a feel of fomo. Fomsumerism approach can be a helpful and reasonable structure for context of social media-driven consumption. This approach allows to investigate dimensions that determine motives, including social acceptance, self-esteem, self-branding, social comparison. One of the most extensive and common determinants of fomsumerism evaluated is share-based interaction.

\section{Centrality of Fomo}

Many issues concerning fomsumerism may be considered in the applications regarding social media world, including causes and consequences of fomsumerism, the social norms, social groups, reference groups, social class, motivations, behaviors, attitudes, perceptions, and personality characteristics of social media user. For many young consumers, for instance, shares and comments on social media are indispensable to their lives and identities. Especially, fomsumerism is a fundamental component of a young consumer's behavior regarding social media interactions, and some consumers discover an interesting emotion, tendency and orientation in consumption during their interactions with their peers.

The emergence of a fomsumerist tendency among heavy user of social media is not only observed by consumer behavior scientists, but it has attracted interest from researchers in social media and internet studies as well. Despite the fact that the title of fomsumerism or fomsumerist is not used as a label, many of the studies on fomo can be inferably related to consumption. The fomsumerist tendency has been associated with a growing popularity of prevalence and the commercialization of social media tools.

Perspective of fomsumerism focuses on attitudes, cognition, instant mood and behavior in the world of social media. However, there has been little research on how the fomo phenomenon affects behavior within the 
fomsumerism theoretical framework. Given these theoretical explanations for fomsumerism in the social media context, attention now turns to evaluating consumer behavior in order that individuals' motives for deciding on product-related experiences in the peer actors in the social media marketing. Fomsumers place fear of missing out (fomo) at the center of their lives. It can be describe as a social media based life-style in which a high level of attachment to individuals in social media as a satisfaction and serves as a set of wellbeing and happiness. The patterns of consumption that social media and fomo reveal can be regarded as consumerism. Fomsumerism thus lends meaning to life and provides an aim for daily social media endeavors. This phenomenon is also reflected in the share of consumers in social media.

\section{Theoretical Foundations of Fomsumerism}

This article brings together the different theories regarding social media, consumption, sociology and psychology, and consumer behavior. Studies on consumer behavior and social media suggest that fomsumerism is significantly associated with theories such as social comparison, self-presentation, social anxiety, conspicuous consumption and brand jealousy (see e.g. Leary, 1983, 1990; Sarkar and Sreejesh, 2014; Veblen, 1994). Theory of fomsumerism is distinguished from theories of consumption or marketing by six characteristics: the desire to participate at the activity (emulation), the need to show or exhibit the product (conspicuous consumption), the need to social acceptance or approval, self-actualization, the need of integration of social media, desire to build an attractive personal and social identity.

Other theoretical approaches (e.g. self-presentation theory, expected utility theory, belongingness theory and self-market or brand) predict that the effects of social media on purchasing decisions enables individuals to pursue approved and non-excluded decision or to achieve status. Furthermore, fomsumerism is considered to shape social relations and purchase factors related to online consumer behavior and social media marketing. Correspondingly, we adopt based on a reciprocal interaction (fomo and consumption) of fomsumerism as the effect of fomo on preferences for product, service or event. It may be viewed as a combination of self-esteem, status, or socially desire to be liked consumer behavior that involves a 'fomsumerist' perspective and may thus be called 'socially concerned consumption'

These theories have been closely tied with fomsumerism activity, such that in the face of social media preference or fear of exclusion, fomsumers are likely to rise to action. Due to the hidden and largely unidentifiable nature (e.g., subconscious) of fomsumer groups, such product choices are primarily affected from many theories regarding social media. Furthermore, it is both meaningful and important to explore whether patterns in social media posts and prevalence of teenagers' perceptions predict consumption behaviors. Regarding peer fomsumer behaviors, many theories on social context suggests that the degree to which known others act on a particular behavior influences one's own willingness to engage in that behavior. Regarding fomsumer behaviors, many theories on social relationship or comparison suggests that the norms to which accepted by the group act on consumption behavior influences consumer's own willingness to engage in that behavior. This willingness is reflected in a covertly forced situation by the social norms.

\subsection{Acquisition as Pursuit of Conspicuous Consumption}

Consumption is not only a way of solving problems or satisfying physical needs, but also a marker of social status, as described by Veblen more than 100 years ago (Veblen 1994 [1899]), and even shaping personal identity. One of the most important indicators of social status is related to the meaning of consumption made, which is conspicuous consumption. In addition, as mentioned above, statue based fomsumerism and a self-brand lifestyle are evaluated as an indicator of attract attention of social group. Additionally, fomsumerism, somehow, is also associates with consumerism which is identified with identity through consumption (Trentmann, 2004), luxury, prestigious consumption (Ali, 2006). At present, the literature on fomo-based consumption and its impact on product or services, particularly conspicuous and luxury consumption, is still emerging and predominately focuses on experience sharing. However, the nature effect of fomo on behavior in consumption has involved not only luxury behavior but also social marketing projects.

The second issue we will address regarding conspicuous consumption concerns the materialism about fomsumerism. For this reason, concept of materialism that can be associated with conspicuous consumption can be apply to explain the phenomenon or theory of fomsumerism. The millennial generation consumes the products or services as a means of desired lifestyle, symbols and self-expression. For this reason, it is possible to say that young generation is more open to conspicuous products or services (Kim \& Jang, 2014), such as luxury restaurants, mobile phones, sport brands. On the other hand, millennials give considerable attention to materialism to deal anxiety by possessing specific brands (Bıçakcığlu, Ögel \& İlter, 2017; Richins and Dawson, 1992; Sharpsteen, 1993). Furthermore, since materialism encourages possessiveness desires, jealousy in 
materialistic individuals can be foreground (Belenky, 2008). In this respect, it is possible to associate fomsumerism with jealousy.

\subsection{Social-Based Acquisition and Presence}

Different theories that can be used to explain why individuals make decisions in the social media derives from self-esteem theory. On the fulfilment side, similarly, individuals can be seen as acquiring goods and services in the enviable environment because of lack of self-confidence. Viewed through the lens of self-esteem theory, in consequence, participation in community driven event can be explained as resulting from the existence of personal fulfilment.

Assuming that there is an emerging a new theory regarding the social media consumption, we contemplates theoretically that many theories associated with consumption and social psychology such as self-market/ or self-brand, belongingness, social exclusion, social comparison, self-esteem, expected utility, and scarcity may be integrated in fomsumerism theory. Display of consumption among friends in social media provides a number of 'psychological rewards' and 'social rewards' for the individual, which partially explain his/her motivations. However, there is little known about whether more or less social media-directed individuals are more likely to be consume based on social pressure, exclusion, and acceptance. The psychological rewards can be summed up as self-gratification, demonstration, relaxation, escape, self-expression, and self-actualization. The social rewards include: social approval, group integration, and social attraction. Aside from the matter of the self-branding, it appears that the social comparison has to address behavioral patterns as social visibility and acceptability means also, from the perspective we just take into consideration. Consider, for instance, the link between self and others, which is of critical importance to the level of ownership, since one thing the self-image does is to increase the image of product in the social media environment. This explanation on fomsumerism is in line with the belongingness theory that consumers want to belong to a group as a social entity. In light of these theoretical approaches, many of the existing explanations on consumption have focused on finding evidence on the impact of social and psychological factors. In particular, explanations in consumer behavior in different social media circumstance have been utilized to assess the role of fomo on consumption. Similarly, these explanations are in line with the idea that fomsumers who have a more positive view of shares in social media are likely to participate the events in the next times. This foresight is also reasonable since consumers who want to be more noticed would be expected to be more appealing of the way their sharing naturally appear.

Social exclusion is, of course, a social notion of concern central to acceptance rule of social media, but contemplated herein within the broader context of new media stratification. In terms of millennial consumers, peer pressure is an important indicator for consumption (Fromm \& Garton, 2013; Kim \& Jang, 2014). One of the indirect theories regarding acquisition and presence is social exclusion theory. Social exclusion theory is based on anxiety that underlines the fear of being excluded from an important social group (Bıçakcioğlu, Ögel \& İlter, 2017; Leary, 1990). Thus, the concern that consumers feel about dissatisfaction may be decisive in fomsumerism. It is possible to say that this applies to peer pressure in social media. The concept of fomo is prevalent among Millennials because they exchange far more social information through social media utilities than the previous generation (Przybylski et al., 2013). These consumers make decision according to their peer opinions such as looking good (Barker, 2012; Taken Smith, 2012). For instance, millennial fans are more likely go to games when their peer believe that "being cool" is the main value to make a difference. According to Yim (2015), fomo is an indicator for fans following their teams. This pattern can be applied to many other consumption behaviors, such as party attendance, social meeting participation, and integration for entertainment event.

\subsection{Acquisition as Pursuit of Happiness and Instant Gratification}

Today, one of the trends that fomsumers pursuit is instant happiness or gratification. Lu and Gilmour (2004) states that many American people evaluate happiness as the highest possible value in life. For some, happiness is the supreme goal in life. Philosophy of "Happiness is life!" shaped also many of behavior in terms of consumption. This feeling regards imposed of postmodern world and fast-flowing life. Those who pursue instant pleasure, especially millennial consumers, cause marketers to focus on faster reacting strategies regarding social media marketing. Similarly, many shares on social media have indicated fomsumerism as inherently satisfaction and instant pleasure. One of the reasons that instant gratification or hedonism are so central to fomsumers is that they view the sharing and interaction in social media platforms as essential to their pleasure and satisfaction in social life. Instant happiness and gratification, however, points out to be superficial and shallow. As indicated by Dossey (2014), high fomo are linked to low levels of need satisfaction and life satisfaction. In other words, a consumer who feels highly excluded from a social group is enjoying low levels of life. For this reason, marketers positioning the experience, service and product as an opportunity not to be missed. The emphasis on instant 
consumption and scarcity can be evaluated as a marketing strategy that will especially be effective in fomsumerism and experiential activities.

\subsection{Self-Branding and Promotion}

The many studies (e.g., Heinonen, 2011; Park, Kee \& Valenzuela, 2009; exploring social media show similar findings in terms of gratification or motives, such as self-actualization, self-expression, social interaction, entertainment, self-status seeking. Prior to the age of social media, personal brands were influenced by just a few things, as stated by Reynolds (2013). However, in the age of social media we are in, there are many communication channels affecting self-banding. One of them is social media. Tools of social media such as Facebook, Instagram, and Pinterest acts as an intermediary in shaping and conveying the image. The spread of social media among users has been an important instrument in the emergence of the fomo phenomenon. A focal point in the literature relating fomo consumption has been around the prevalence of self-branding (McDermott, 2017) and sharing-motivated experience in marketing. Fomo is used by individuals to self-market and self-brand an ideal 'self' (McDermott, 2017). There exists a seeming falsehood of the creation of a mediated self as what one portrays as their own is socially sanctioned. Individuals use extensively social media tools to positioning themselves as they desire. Self-presentation theory underlies the notion of that individuals are motivated to make desired impressions on others to cope with social anxiety (Bıçakcığlu, Ögel \& İlter, 2017; Leary, 1983; Schlenker and Leary, 1982). For self-market or self-brand, fomsumerism is considered as the process of improving the image of self which is indicated by outcomes that measure current status regarding social perception, comparison with others, coverage of the message, persuasiveness, and naturalness of shared message.

\section{Discussion and Conclusion}

This article is a pioneering theoretical work as an approach from the perspective of combination of fomo and consumption. Accordingly, the aim of this article was to conceptualize the fomsumerism in terms of consumer behavior and to discuss this phenomenon, concept or theory. This study provides needed clarity for scholars approaching this topic. Fomsumerism can be evaluated as a new form of consumption regarding social media. This article has demonstrated the existence of consumer's fomo tendencies and effects on consumer behavior. The review of current literature on relationship between fomo and consumer behavior reveals that fomsumerism can be viewed as a phenomena associated with market environment of new era. In this theoretical study, the fomsumerism can be considered a strategy by which an individual chooses a product, service or event based on group pressure in social media.

Clearly, the social media that are characterized as new life temples are likely to give way to consumption patterns. Fomsumerism points out a deep phenomenon with meaning beyond consumption. In this sense that the notion of fomsumerism can be said to be of more online interactions than consumption per se. Thus, consumerism, especially for young people or teenagers, is a way of social media based life. From this point of view, fomsumerism can be characterized as a means of expressing self in social media. Rather, certain aspects of fomsumerism, particularly statue and intend to participation, might be associated with social comparison. In line with suggestions that shares and selfies on Facebook or Instagram do contribute directly or indirectly to young consumers' happiness, wellbeing and, leisure and satisfaction. This is an important message, although difficult to find out the motivations underlying behavior in social media where topics covered with different messages or images.

Some scholars working on social media have argued that individuals and societies in the internet age are part of on online world-driven consumption. Fomsumerism can positively and negatively impact individuals according to social media interactions. In terms of its positive effect, social media tendencies for heavy users shape consumption patterns. An important inference here is that heavy user young tend to be more fomsumers-much more so than middle ages or older people. There is strong acceptance that fomsumer poses an increasing incentive to share in social media. It is possible to say that individuals who act according to the group that they are more passive, more loyal, form the target group of the fomumerism. However, some of theoretical explanation (such as self-esteem level and self-theory) also demonstrates that fomsumerism can have a negative impact on independent and original decision making. The negative factors may include reduced the effect of popular promotions or advertising through social media, sense of self-realization, compulsive buying, and uniqueness among others. In addition, it is possible to say that the self-realizing individuals tend to show more resistance to fomsumerism. Also, it can be said that these individuals may be away from fomsumerism by acting in the sense that individuals with self-esteem characteristics will not consume for others.

The explanations from a fomsumer perspective, rather than the fomo perspective, have theoretical implications. 
Evaluating the theories separately, we assume that it is not enough to see the comprehensive and depth of fomsumerism. For this reason, an integrated theoretical approach to fomsumerism are most suitable. This theoretical study can contribute to the strategies for social media marketing that have been discussed in the review of the literature. For example, the fomsumerism perspectives can be applied in many products, services or experiences to design applications of social media, or it can be employed in virtual brand groups to determine the level of comsumption in a particular group of consumption. Finally, many companies or organizations can use this new tendency to know on which dimensions of fomsumerism they should focus. As such, social media marketers should examine youths' evaluations of likes, posts, and choice likelihood through a fomo.

In conclusion, this theoretical framework suggests it may be important to reveal the notion that fomsumerism in general represents the hidden patterns of consumption behavior of social media in today's world. This paper contributes to marketing theory by developing a conceptual approach that explains and offers implications pertaining to the relationship between fomo and consumption in the age of social media. It can be assumed that the increasing of fomsumerist paradigm in social media age has extended the traditional approaches of consumer behavior to online based products or services. Fomsumerism, however, appears to have innovative part of social media marketing. A stronger implication for the use of consumption regarding fomo is also likely to be related with the presence of convincing evidence that the condition in question is in fact a need satisfaction and elimination of deficiencies.

As this study is a pioneering work on fomsumerism, it will naturally have limitations within its scope. In interpreting our results, it must be kept in mind that the level of approval for social media use for the consumption of a specific aim is the result of a combination of several factors in addition to the ones considered here. To deserve the fomsumerism theory in the literature, it needs to be supported by applied researches. In this study, related-concepts and theories on fomsumerism were tried to be explained. It will be possible to shed light on the future with further studies and, more concepts and explanations should integrate to better understand the phenomenon or theory of fomsumerism. Correspondingly, research is needed to understand how individual's fomsumeristics tendencies could be effectively managed or transformed.

\section{Acknowledgments}

This paper received a support of research incentive projects (Pr. N: 1705S347) from Anadolu University Scientific Research Projects.

\section{References}

Abel, J. P., Buff, C. L., \& Burr, S. A. (2016). Social media and the fear of missing out: Scale development and assessment. Journal of Business \& Economics Research (Online), 14(1), 33-44. https://doi.org/10.19030/jber.v14i1.9554

Ali, A. J. (2006). Survey of Management and Organization, American Society for Competitiveness, Indiana, PA.

Barker, V. (2012). A Generational Comparison of Social Networking Site Use: The Influence of Age and Social Identity. International Journal of Aging and Human Development, 74(2), 163-187. https://doi.org/10.2190/AG.74.2.d

Belenky, M. (2008) The Anxiety of Dispossession: Jealousy in Nineteenth-century French Culture. Plainsboro, NJ: Associated University Press.

Bıçakcıoğlu, N., Ögel, İ. Y., \& İlter, B. (2017). Brand jealousy and willingness to pay premium: The mediating role of materialism. Journal of Brand Management, 24(1), 33-48. https://doi.org/10.1057/s41262-016-0016-2

Coons, J., \& Chen, S. L. S. (2014). Social Network Analysis for Facebook: Locating Cliques and Visualizing Sociability. In Symbolic Interaction and New Social Media (pp. 43-61). Emerald Group Publishing Limited. https://doi.org/10.1108/S0163-239620140000043013

Dossey, L. (2014). FOMO, digital dementia, and our dangerous experiment. Explore: The Journal of Science and Healing, 10(2), 69-73. https://doi.org/10.1016/j.explore.2013.12.008

Doster, L. (2013). Fear of Missing Out: Is Voyeurism the Real Motive Behind Teen Consumption of Social Media?. ACR European Advances.

Fromm, J., \& Garton, C. (2013). Marketing To Millennials: Reach The Largest And Most Influential Generation Of Consumers Ever. New York: AMACOM, American Management Association.

Hayran, C., Anik, L., \& Gurhan-Canli, Z. (2016). Exploring the Antecedents and Consumer Behavioral 
Consequences of "Feeling of Missing Out" (Fomo). In P. Moreau \& S. Puntoni (Eds.), NA-Advances in Consumer Research (Vol. 44, pp. 468-469). Duluth, MN: Association for Consumer Research.

Hayran, C., Anik, L., \& Gürhan-Canli, Z. (2017). Exploring the Antecedents and Consumer Behavioral Consequences of "Feeling of Missing Out (FOMO)". In Creating Marketing Magic and Innovative Future Marketing Trends (pp. 661-662). Springer, Cham. https://doi.org/10.1007/978-3-319-45596-9_127

Heinonen, K. (2011). Consumer activity in social media: Managerial approaches to consumers' social media behavior. Journal of Consumer Behaviour, 10(6), 356-364. https://doi.org/10.1002/cb.376

Hodkinson, C. (2016). 'Fear of Missing Out' (FOMO) marketing appeals: A conceptual model. Journal of Marketing Communications, 1-24. https://doi.org/10.1080/13527266.2016.1234504

JWTIntelligence. (2012, March). Fear of missing out (FOMO). Retrieved November 28, 2017, from JWT: http://www.jwtintelligence.com/wp-content/uploads/2012/03/F_JWT_FOMO-update_3.21.12.pdf

Kim, D., \& Jang, S. S. (2014). Motivational drivers for status consumption: A study of Generation Y consumers. International Journal of Hospitality Management, 38, 39-47. https://doi.org/10.1016/j.ijhm.2013.12.003

Larkin, B. A., \& Fink, J. S. (2016). Fantasy Sport, FoMO, and Traditional Fandom: How Second-Screen Use of Social Media Allows Fans to Accommodate Multiple Identities. Journal of Sport Management, 30(6), 643-655. https://doi.org/10.1123/jsm.2015-0344

Leary, M. R. (1983). Social anxiousness: The construct and its measurement. Journal of Personality Assessment, 47(1), 66-75. https://doi.org/10.1207/s15327752jpa4701_8

Leary, M. R. (1990). Responses to social exclusion: Social anxiety, jealousy, loneliness, depression, and low self-esteem. Journal of Social and Clinical Psychology, 9(2), 221-229. https://doi.org/10.1521/jscp.1990.9.2.221

Lu, L., \& Gilmour, R. (2004). Culture and conceptions of happiness: Individual oriented and social oriented SWB. Journal of Happiness Studies, 5(3), 269-291. https://doi.org/10.1007/s10902-004-8789-5

McDermott, R. (2017). "FoMO and the Image of the Self from College Campuses to Madison Avenue" (2017). Honors Theses and Student Projects. 60. Retrieved December 29, 2017, from http://digitalworks.union.edu/theses/60

Park, N., Kee, K. F., \& Valenzuela, S. (2009). Being immersed in social networking environment: Facebook groups, uses and gratifications, and social outcomes. CyberPsychology \& Behavior, 12(6), 729-733. https://doi.org/10.1089/cpb.2009.0003

Przybylski, A. K., Murayama, K., DeHaan, C. R., \& Gladwell, V. (2013). Motivational, emotional, and behavioral correlates of fear of missing out. Computers in Human Behavior, 29(4), 1841-1848. https://doi.org/10.1016/j.chb.2013.02.014

Reynolds, M. (2013). Personal Branding with Social Media. eBookIt. com.

Richins, M. L., \& Dawson, S. (1992). A Consumer values orientation for materialism and its measurement: Scale development and validation. Journal of Consumer Research, 19, 303-316. https://doi.org/10.1086/209304

Sarkar, A., \& Sreejesh, S. (2014). Examination of the roles played by brand love and jealousy in shaping customer engagement. Journal of Product and Brand Management, 23(1), 24-32. https://doi.org/10.1108/JPBM-05-2013-0315

Schlenker, B. R., \& Leary, M. R. (1982). Social anxiety and self-presentation: A conceptualization model. Psychological Bulletin, 92(3), 641-669. https://doi.org/10.1037/0033-2909.92.3.641

Sharpsteen, D. J. (1993). Romantic jealousy as an emotion concept: A prototype analysis. Journal of Social and Personal Relationships, 10(1), 69-82. https://doi.org/10.1177/0265407593101005

Taken Smith, K. (2012). Longitudinal study of digital marketing strategies targeting Millennials. Journal of Consumer Marketing, 29(2), 86-92. https://doi.org/10.1108/07363761211206339

Trentmann, F. (2004). .Beyond consumerism: new historical perspectives on consumption. Journal of Contemporary History, 39(3), 373-401. https://doi.org/10.1177/0022009404044446

Veblen, T. [1899] (1994). The Theory of the Leisure Class (2nd ed.). London: Constable Press.

Ward, D. M., Dill-Shackleford, K. E., \& Mazurek, M. O. (2018). Social Media Use and Happiness in Adults with Autism Spectrum Disorder. Cyberpsychology, Behavior, and Social Networking, 21(3), a205-209. 
https://doi.org/10.1089/cyber.2017.0331

Yim, H. I. (2015). Identifying the Critical Factors in Sport Consumption Decision Making Process for the Millennial Sport Fans: An Application of Model of Goal-directed Behavior (Doctoral dissertation, University of Georgia).

\section{Copyrights}

Copyright for this article is retained by the author, with first publication rights granted to the journal.

This is an open-access article distributed under the terms and conditions of the Creative Commons Attribution license (http://creativecommons.org/licenses/by/4.0/). 